\title{
Uma nova perspectiva para os jovens leitores: o livro impresso digital
}

\section{A new perspective for young readers: the digital printed book}

\author{
Manaíra Aires Athayde*
}

Resumo: Propomos pensar como o desenvolvimento de novos formatos do livro impresso pode torná-lo parte do paradigma digital e atrair jovens leitores, leitores de uma geração cuja subjetividade é construída por um mundo digital e em contínua permanência online.

Abstract: We propose to think about how the development of new formats of the printed book can make it part of the digital paradigm and attract young readers, readers of a generation whose subjectivity is constructed by a digital world and a permanent online status.

Palavras-chave: literacia, livro impresso, paradigma digital, mudança de paradigmas. Keywords: literacy, printed book, digital paradigm, change of paradigms.

\footnotetext{
* Universidade de Coimbra.
} 
A problemática da literacia é resoluta: a crescente diminuição das competências de leitura - dentre elas a capacidade de detectar temáticas, fazer inferências, construir argumentos interpretativos - tem se agravado nas últimas gerações, sobretudo nas mais jovens, em sociedades que, ainda fundadas nos paradigmas da tecnologia impressa (sobretudo nos canais bastante delineados da leitura e da escrita), não só assistem mas participam de maneira cada vez mais célere na imanência digital.

No Brasil, um dos mais completos estudos a respeito foi divulgado em 2012 pelo Instituto Paulo Montenegro (IPM), que ao entrevistar mais de duas mil pessoas entre os 15 e 64 anos de idade revelou um contingente de $38 \%$ de estudantes que não consegue interpretar textos, comparar informações e fazer cálculos que exigem mais de uma operação matemática. Iniciada em dezembro de 2011 e concluída em abril de 2012 , a pesquisa revela ainda que $4 \%$ dos futuros diplomados em curso superior são analfabetos funcionais e $70 \%$ das redações feitas por quem está na faculdade tem pelo menos um erro de português em cada frase. O resultado é que, tendo essa mesma pesquisa sido realizada em 2001, mostra que em uma década aumentou em $58 \%$ o número de estudantes do ensino médio e superior que não conseguem compreender plenamente o que lêem (cf. O Dia, 2012).

Um outro estudo de referência na área, dessa vez abrangendo uma comparação que envolve duas décadas, é o Reading at Risk: A Survey of Literary Reading in America, relatório realizado pela National Endowment for the Arts numa pesquisa envolvendo mais de 17 mil entrevistados nos Estados Unidos. Uma das constatações a que se chega é que entre 1982 e 2002 o número de leitores de livros literários caiu 10\%, o que representa uma perda de 20 milhões de leitores em potencial. Em 2002, 67\% dos graduados universitários estavam engajados em leituras literárias frequentes, em comparação com 73\% em 1982. Uma das conclusões mais importantes do estudo é que o hábito da leitura frequente de livros impressos está em declínio entre pessoas de todos os níveis de ensino e em todas as faixas etárias, mas que se averigua uma catalisação maior quando se trata das faixas etárias mais jovens: em 1982, pessoas entre os 18 e os 34 anos formavam o grupo mais propenso à leitura, enquanto em 2002 foi este o grupo menos predisposto (cf. Azzam, 2005).

Acontece que, enquanto "a leitura de livros impressos e de géneros literários tem diminuído ao longo dos últimos vinte anos, [...] as pessoas em geral, e os 
mais jovens em particular, fazem leituras no ecrã de materiais digitais mais do que nunca" (Hayles, 2012, p. 57), acabando por facultar que se associe que o aumento de leitores digitais está diretamente relacionado à diminuição de leitores de conteúdos impressos. E muitas vezes os media têm fulcral participação na promoção desse argumento, com um discurso que reforça a substituição do impresso pelo digital. A ver, por exemplo, o artigo divulgado pela Consultora OThink, que revela uma pesquisa realizada com cerca de mil brasileiros em 2011 que responderam à enquete «No ano 2050, haverá livros, revistas e jornais impressos em papel?», na qual 52\% dos entrevistados responderam "sim», 33\% alegaram que «não» e 15\% apontou não ter opinião quanto ao assunto (cf. Assis \& Pereira, 2011).

Essa correlação deliberada entre a existência cada vez maior de leitores digitais que lêem cada vez menos textos impressos, no entanto, pode tornar-se um falso dilema, porque o que deve estar fundamentalmente em análise não é a possibilidade de substituição de uma modalidade pela outra mas em que medida a leitura em plataformas digitais pode acrescer às competências de leitura desenvolvidas até hoje sobre os padrões da literacia associada ao impresso. Ou seja, o que está em pauta aqui não é pensar a retroação do códice analógico do papel em função do digital, mas pensar na forma como o meio digital (quer pelas novas estruturas de pensamento que faculta, quer pela instrumentalização que viabiliza com os programas de edição e designer) pode servir para re-imaginar o que é paginar o livro, transitando por um processo que se estende, então, do analógico ao digital. Assim, a perscruta ressonante é: como a mediação digital tem sido usada para intensificar a experiência do códice impresso?

Ao longo dos séculos XIX e XX, o desenvolvimento do regime de representação dos média concorreu com os regimes de representação baseados na letra e na escrita. Nas últimas décadas a literacia digital acelerou a contaminação entre a escrita da letra e a escrita do dígito. Enquanto corpo instável de textos e práticas discursivas, a instituição da literatura sofre agora os efeitos da textualidade eletrônica (Portela, 2012, p. 05).

Antes de mais, aliás, é preciso apresentar o debate que existe a respeito dos moldes do close reading diante das exigências dos novos tempos e suas mídias. Para investigadores como N. Katherine Hayles (2008) e Susan Schreibman 
(2013), o close reading, da maneira como é tradicionalmente praticado, tornou-se um método que não consegue mais lidar com a complexidade da literatura do século XXI, permanecendo ainda apenas porque assumiu um lugar proeminente como a essência da identidade disciplinar. Ele constituiria, sob essa óptica, a maior porção do capital cultural de que os estudos literários se socorrem para provar o seu valor à sociedade, a saber a própria caracterização do método de leitura, com atenção precisa e detalhada à retórica, ao estilo e à escolha da linguagem, análise de palavra a palavra nas técnicas linguísticas, apreciação e articulação do valor estético de um texto e capacidade de totalização.

Se para isto atentarmos, veremos que é preciso mais do que encorajar a transferência de competências da leitura impressa para o digital e vice-versa, mas perceber que o digital e o impresso não são ramificações distintas de mesma natureza e que, por isso, não podem ser comparados modalmente, o que permite inclusive que o digital seja uma manifestação estrutural da forma impressa, como demonstraremos mais adiante. Ora, aqui problematizamos a noção de digital, que não se refere somente ao mundo virtual em rede online, mas, sob o conceito de Manuel Portela (2012), a toda uma estrutura que, independentemente do suporte, está atrelada à organização multilinear ou hipertextual, à interatividade, à intertextualidade e ao dinamismo. Ao pensar nesse conceito de digital, podemos ainda questionar: "de que forma os processos materiais e as tecnologias de inscrição criam espaços performativos e modos de presença dos quais depende a produção de sentido?" (Portela, 2013, p. 15).

Chegamos, então, ao ponto fulcral deste artigo. Alinhavando a formulação sobre o conceito de digital aos dados que expusemos no início, que revelam a diminuição das competências de leitura sobretudo entre os jovens, propomos pensar o desenvolvimento de novos formatos do livro impresso como um dispositivo dinâmico e com estruturas emuladas, e que assim atue como um importante recurso da literatura no século XXI para atrair as novas gerações, fazendo com que elas possam aceder a um mundo impresso que faça parte do paradigma digital. Afinal, são essas mesmas gerações que já se encontram inscritas numa "cultura que tem sido descrita cada vez com mais frequência como uma cultura do software, isto é, como uma cultura cujas práticas e formas são mediadas e determinadas por programas digitais" (Portela, 2012, p. 06). Quer dizer, "a ubiquidade da mediação digital significa que se torna hoje difícil circunscrever práticas e formas artísticas que não tenham, em menor ou maior grau, integrado 
as novas condições materiais de produção nos seus processos" (ibid.). O livro impresso, desnaturalizado de seus modelos tradicionais, pode, assim, vir a funcionar como um programa digital, tal como nas obras The Life and Opinions of Tristram Shandy, Gentleman; Tree of Codes; Composition No.1; e Kapow!.

Mencionar estes livros, aliás, todos pertencentes à editora Visual Editions, fundada pelos designers Anna Gerber e Britt Iversen em Londres em 2010, agrega à discussão um outro importante fator, que é a reação editorial a um mundo cada vez mais fundamentado em diretivas digitais. Afinal, de que forma editoras como essa têm assumido o processo de revitalizar e dinamizar o meio impresso?

Alguns indícios nos são logo dados quando atentamos para o catálogo da Visual Editions, pelo que percebemos alguns traços de convergência entre as obras. Um deles é o fato de a editora adotar livros que fizeram sucesso há décadas ou mesmo há séculos e conferir-lhes, modificando totalmente a maneira de se olhar para eles, uma nova disposição visual, como em The Life and Opinions of Tristram Shandy, Gentleman (2010) e em Composition No.1 (2011), ou mesmo radicalizando essa experiência, como veremos no caso de Tree of Codes (2011); ou livros que levam para o seu núcleo de composição assuntos atuais que mobilizam a mídia internacional, como no caso de Kapow! (2012), cujo cerne narrativo está concatenado a questões que envolvem a Primavera Árabe, inclusive evidenciando a forma como os new media e as redes sociais tiveram relevância na organização das manifestações revolucionárias que surgiram em 2010 no Oriente Médio e no Norte da África.

A própria narrativa de Kapow!, aliás, evoca as novas formas de se dispor as informações, ou mesmo as novas formas de se comunicar, que surgiram a partir da plataforma digital e que foram potencializas com a criação de redes como o Twitter, o Facebook e o Youtube, como alega o próprio autor, o escritor britânico Adam Thirlwell, num vídeo disposto no site da editora. Thirlwell traz esses novos modelos informacionais para a sua obra por meio de vazamentos de textos diagramados dentro e fora de parágrafos, facultando progressivamente informações que ora o narrador não sabe, ora ficaram dispersas nas digressões do narrador, tal como acontece conosco num mundo que, já assente no paradigma digital, é caracterizado por uma avalanche de informações, em que agora os receptores são também produtores no sistema de produção da informação. Uma avalanche difícil de administrar, uma vez que o utilizador (longe de ser somente um espectador) mal consegue se situar em meio a tantas informações, e na qual 
cada vez mais se dilui as noções de verdadeiro e de falso, de descrição factual e de opinião.

Kapow!, afinal, é um livro guiado por um monólogo em "alta-velocidade", como o são as coisas nesse século XXI, a partir de um narrador em trânsito, literalmente, num mini-cap em Londres conduzido por um taxista egípcio. Um narrador representante dos excessos, "over-doped, over-caffeinated, overweight", numa crítica mordaz a um mundo que exige que tudo seja muito e cada vez mais, e interligado a um grupo de personagens em que cada um vai sendo transformado pela ideia de revolução. A noção de uma interconectividade contínua (entre personagens, entre histórias e na própria disposição dos textos, que permite que eles estejam sempre a interferirem uns nos outros) tenta criar uma história em "real time", lembrando os atuais modelos de comunicação instantânea. Assim, o próprio livro, sendo um livro sobre revoluções, também apresenta uma amplitude de movimento: a incerteza de onde um momento começa e de onde ele pára (e ao parar ele nunca termina, evidenciando um processo narrativo que estará sempre inacabado por definição ou natureza), e a percepção de que nada acontece em linhas retas, em linhas resolutas.

Não por acaso as páginas de Kapow! se desdobram e podem ser lidas em múltiplas direções, de modo que não há uma orientação para se ler o livro e a própria figura da capa da obra já assim sugere ao ser colocada de cabeça para baixo, contrariamente ao título e ao nome do autor. "De cabeça para baixo, aliás, é como o nosso mundo está - e talvez não seja tão ruim assim" é uma das mensagens visuais que apreendemos. Um mundo de cabeça para baixo quiçá seja o boom necessário enquanto entalpia para determinadas transformações que não se sabe bem para onde apontam, lê-se nas entrelinhas desse livro, cujo próprio título identifica uma explosão, recorrendo ao uso da expressão onomatopaica kapow! utilizada em histórias em quadrinhos para simbolizar um estouro, um boom. A onomatopeia ganha ainda mais pujança na capa porque o ponto de exclamação é paginado em grande dimensão e centralizado, escondendo um dos olhos da rainha Marie Antoinette, numa imagem em que o seu rosto aparece "recortado" do retrato pintado por Jean-Baptiste Gautier Dagoty em 1775, quase duas décadas antes de ela ser guilhotinada no início da Revolução Francesa (e aqui o simbolismo em torno da ideia de revolução é perspicaz).

A pintura de Marie Antoinette editada na capa de Kapow! faz-nos lembrar, não obstante, do traço editorial sobre o qual falávamos anteriormente. Nessas 
obras chamadas de "visual writing" (cf. Cole, 1997), o nosso presente, com todas as suas céleres revoluções tecnológicas, nunca é olhado sem se ter em conta o passado, e por isso mesmo muitos desses romances conseguem que passe por eles uma certa linha progressiva da literatura. Quer dizer, não negligenciam as manifestações romanescas anteriores e muitas vezes as incorpora no processo como base para uma nova criação (basta ver o exemplo dos livros que já existiam e que tiveram as suas narrativas decisivamente alteradas a partir da reelaboração visual), de tal forma que a identidade visual desses livros tem em si uma fusão temporal. Ora, os elementos dessas obras, com tamanha experiência visualmente imersiva, são criados em esferas de simultaneidade, que por sua vez substituem a temporalidade, a causalidade ou a sequencialidade num novo espaço de criação, que deixa de ser definido pela linearidade de relações causais ou sequenciais para ser firmado por relações simultâneas que substituem a posição teleológica pela contingência de mundo.

Um livro como o Kapow!, por exemplo, ao falar sobre a organização multilinear de um mundo onde, embora existam percursos, eles são cada vez menos lineares e previsíveis, fala sobre a sua própria estrutura, ou fala com a sua própria estrutura. Manifesta-se assim como se manifestam, portanto, os fluxos de comunicação, considerando que se na maior parte do século passado eles atendiam ao modelo linear de emissor-mensagem-receptor descrito por Roman Jakobson, agora esses elementos existem exortados num tempo plurilinear e heterárquico, não mais concebido como uma sucessão de períodos, mas como um presente que, fixo em si enquanto se move adiante, é atingido por várias linhas de eventos/fatos/informações com sentidos e direções diferentes, o que acaba por gerar novas relações entre a forma e o conteúdo.

A visual writing não olha para a forma enquanto invólucro do conteúdo, mas revitaliza a sua noção, concebendo a forma de modo que ela altere radicalmente o conteúdo porque é ela própria também conteúdo, parte imprescindível dele. Basta ver como parecem perfeitamente naturais as interrupções narrativas com a disposição dos textos de distintas maneiras (uma mancha textual é diagramada em oblíquo, outra a interfe no sentido de baixo para cima, outra ainda é lida em coluna vertical da direita para a esquerda, por exemplo, de tal forma bem dispostas que não se cria ruídos visuais que não sejam aqueles pretendidos pelo autor). A naturalidade surge porque as próprias interrupções são parte indistinta do conteúdo textual e estão sempre a nos lembrar como vivemos agora, com o 
advento dos novos meios de comunicação, sendo sempre interrompidos por um e-mail, uma mensagem no chat, um SMS, uma chamada telefônica.

Assim, na perspectiva da visual writing, escrever é também diagramar, e a figura do escritor confunde-se com a do designer ou do artista gráfico, cogente na exploração dos mecanismos que criam um mundo digital em papel impresso. Editoras como a Visual Editions, desse modo, levam novas experiências à leitura do livro impresso criando livros projetados para serem lidos.

Vejamos como no caso do Tree of Codes, do norte-americano Jonathan Safran Foer, temos um livro com um die-cut diferente a cada página, isto é, cada lauda é formada por um texto escrito que tem determinados trechos literalmente cortados e em seu lugar podem ser vistos pedaços do texto da lauda seguinte ou então apenas os recortes que se sucedem. Apesar de ter considerado trabalhar em sua obra com vários textos extraídos de terceiros, o autor decidiu adotar um único livro, aquele que diz ser o seu preferido, The Street of Crocodiles, uma coleção de contos publicada em 1934 pelo escritor polaco Bruno Schulz. Assim, ao apropriar-se de um texto escrito por outro escritor, Safran Foer cria recortes não só a nível hermenêutico mas enquanto intervenção semiótica também, pois esses recortes existem não apenas como condição metafórica mas como realidade material. São construídas, dessa forma, camadas e camadas de memória (materializadas pelos recortes nas folhas de papel e pelo apagamento nelas) sobre os contos, e o fato de ser o livro predileto de Safran Foer é importante justamente para criar essa relação entre os recortes das palavras no texto e a memória afetiva sobre ele.

A narrativa acaba por ser trabalhada, portanto, em função da exploração física das páginas entre si e o resultado não é o The Street of Crocodiles sob outro formato, mas literalmente o Tree of Codes (título, aliás, que resulta do apagamento de letras do The Street of Crocodiles), uma nova história que pode ser lida em vários sentidos e a partir de qualquer lauda, como uma árvore genealógica de códigos a qual podemos explorar partindo de qualquer ponto. "Jonathan Safran Foer, deftly deploys sculptural means to craft a truly compelling story. In our world of screens, he welds narrative, materiality, and our reading experience into a book that remembers that it actually has a body», afirma Olafur Eliasson (2010, s/p) em apresentação do livro.

Não obstante, assim como o Tree of Codes, o Composition No.1 também é uma apropriação de um texto pré-existente, neste caso do conhecido romancis- 
ta experimental e crítico literário francês Marc Saporta, que publicou o original em 1963 e que à época já havia se tornado um romance permutacional de grande impacto, traduzido para vários países. A edição da Visual Editions, lançada em 2011, não apenas traz o livro numa caixa - faz da caixa literalmente uma parte do livro. Uma caixa que traz as páginas soltas, em que cada narrativa é auto-suficiente e a ideia é que as combinações permitam a existência de vários livros dentro de um livro, onde o rumo não é dado pelo autor mas pelo leitor.

Mediante, então, essas permutações que permitem alterar a cronologia dos eventos ou as situações e, portanto, o enredo, tem-se por implicação o que podemos chamar de mise-en-scène, termo aqui adaptado do teatro. Ou seja, um livro impresso digital é pensado de modo tal a requerer que os seus fatores constitucionais exijam uma encenação do leitor (que, assim, passa então a ser um utilizador/usuário) para que a obra seja "ativada". Quer dizer, o que existe é "a noção de ação de um corpo, e o que acompanha e permite o desdobrar deste corpo em cena: o seu movimento e a sua expressão" (Ramos, 2014, p. 60).

É nessa perspectiva que o leitor é convidado a decidir a ordem em que quer ler o livro. Mais do que isto, até: o que se pede em Composition No.1 é que o leitor embaralhe as páginas, como se estivesse num jogo de cartas, esse aspecto nos leva a uma outra importante compreensão do mundo em que as novas gerações crescem: não se trata mais de um mundo onde as crianças e os jovens são educados com o «não toque» ou o «não mexa»; estamos na era touch, em que as crianças já crescem incentivadas a aprender tocando, mexendo. É decerto esta uma das mensagens que apreendemos do vídeo promocional do livro, que mostra um jovem a ler o livro sentado num banco de jardim e, com o vento, as folhas do livro a voarem enquanto ele continua a ler concentradamente a folha que segura, sem se incomodar de forma alguma que as folhas estejam a ser embaralhadas e dispersadas.

Mas a obra não se fica por aqui. Foi desenvolvida também uma versão para iPad, o que faz da edição de Composition No.1 um conspícuo exemplo do que Henry Jenkins chamou de Cultura da Convergência.

Se o paradigma da revolução digital presumia que as novas mídias substituiriam as antigas, o emergente paradigma da convergência presume que novas e antigas mídias irão interagir de formas cada vez mais complexas. O paradigma da revolução digital alegava que os novos meios de comunicação digital mudariam tudo. Após 
o estouro da bolha pontocom, a tendência foi imaginar que as novas mídias não haviam mudado nada. Como muitas outras coisas no ambiente midiático atual, a verdade está no meio-termo. Cada vez mais, líderes da indústria midiática estão retornando à convergência como uma forma de encontrar sentido, num momento de confusas transformações (Jenkins, 2008, p. 31).

A convergência, assim, além de desfazer a ideia da substituição dos medium por outros nomeadamente digitais, concebe antes do processo tecnológico, que une múltiplas funções nos mesmos aparelhos (com a proliferação de canais, acessibilidade e portabilidade), o processo que representa uma transformação cultural, à medida que os públicos são incentivados a procurar novas informações e produtos e a fazer conexões em meio a conteúdos midiáticos dispersos. O próprio fato de que cada livro publicado pela Visual Editions é acompanhado por uma série de vídeos, disponibilizados no site da editora e que mostram desde o processo de montagem às experiências de leitura, constitui um outro traço para o qual atentamos ao olhar o catálogo, do mesmo modo como notamos o fato de que muitas das obras editadas são releituras, conforme explicitamos anteriormente.

Esse universo cultural cada vez mais delineado pelo fluxo de conteúdos através de múltiplos suportes midiáticos, pela cooperação entre variados mercados de mídia e pelo comportamento migratório dos públicos justifica, à medida, por que a versão impressa de Composition No.1 não compete com a sua versão virtual. Os novos leitores, além de espectadores, são agora, na perspectiva de uma convergência midiática, utilizadores de diferentes media em concomitância. E nesse sentido podemos dizer que o processo da convergência adota por completo uma identidade de apropriação, na qual conceitos antigos assumem novos significados, o que se observa inclusive no fato de tanto Composition No.1 quanto Tree of Codes serem livros publicados inicialmente há mais de cinquenta anos e reinventados sob o conceito de um mundo digital, onde se está constantemente a fazer releituras de valores sociais, culturais, econômicos, políticos, só que agora a partir dos próprios meios em que a sociedade se inscreve dia a dia.

O mais paradigmático caso, nesse sentido, é o primeiro livro lançado pela Visual Editions, The Life and Opinions of Tristram Shandy, Gentleman, que na verdade é um romance inicialmente publicado em nove volumes entre $1759 \mathrm{e}$ 1767. Essa obra, do escritor e pastor irlândes Laurence Sterne, já no século XVIII 
transfigurava as convenções do romance e se tornava, assim, precursora em refletir como a criação de elementos visuais e tipográficos pode potencializar o conteúdo textual. Se nessa primeira versão são famosas a página matizada de várias cores para representar o muco nasal e a página negra, que simboliza o luto pela morte de uma das personagens, na versão da Visual Editions há uma re-imaginação visual, em que a página do muco nasal dá origem a uma página vermelha seguida de outra página com a figura de um nariz sobreposta por um triângulo vermelho, e a página negra se torna duas páginas em que o texto é sobre-impresso, criando camadas tipográficas. Gotas de suor são manchas de verniz e uma porta fechada é representada por uma página dobrada, eis ainda outros dois exemplos do que traz a edição de 2010, a qual se seguiram os outros três livros aqui apresentados.

Esses livros subsequentes, por conseguinte, remontam o amadurecimento da visual writing e inscrevem-se no que Espen J. Aarseth (1997) chama de literatura ergódica ${ }^{1}$, pois se em The Life and Opinions of Tristram Shandy, Gentleman o desenvolvimento formal ainda serve, de alguma maneira, a título de ilustração do

\footnotetext{
${ }^{1}$ Nela, Espen J. Aarseth (1997) descreve como especificidades de uma obra digital o dinamismo (capacidade de mobilização); a determinabilidade (estruturas não-lineares, variações dos possíveis fins); a transiência (fugacidade ou instantaneidade ao passo que se pressupõe intensa experiência); a perspectiva (o objeto oferece possibilidade para que seja enxergado de diferentes ângulos); a acessibilidade (facilidade em ser acedido, quer seja a nível de conexão, quer seja por estar em diferentes suportes ou dispositivos); as interligações (capacidade de estabelecer relações diversas com distintos elementos); e a função do utilizador (interatividade, participação ativa do "leitor", agora utilizador ou interator). Markku Eskelinen (2012), por conseguinte, acrescenta a essas "variáveis cibertextuais primárias" a posição do utilizador (a perda de uma leitura linear das relações autor-mensagem-receptor) e o objetivo do utilizador (o leitor/utilizador não tem como compromisso descobrir a "real intenção do autor", mas carrega consigo finalidades próprias injetadas ao processo de interação com o objeto). Já Matthew Kirschenbaum (2008), por viés da estrutura proposta por Espen J. Aarseth, apresenta como "características da materialidade formal" nas tecnologias de inscrição digital a hipertextualidade (ligações internas e externas, que maximizam os percursos associativos intratextuais e intertextuais); a topograficalidade (reorganização topográfica do espaço da escrita); a iconicidade (omnipresença das representações gráficas icônicas); o cinetismo (possibilidade de animação dos signos da escrita); a intermedialidade (ou multimodalidade; processamento integrado de diversos media - escrita, som, imagem, imagem animada); a reticularidade (organização, distribuição e execução em rede dos códigos que geram as representações gráficas dos documentos); e a interatividade (possibilidade de introdução de dados e de ativação de funções pelo utilizador).
} 
conteúdo textual, em Tree of Codes, Composition No.1 e Kapow! o tratamento visual é concebido com o intuito de requerer a participação do leitor na construção do livro, um leitor que assume o papel de "percorrer" o texto, decidindo os caminhos que quer tomar e, consequentemente, manipulando o processo de significação da obra. Assim, esses livros (que em primeira instância trazem sempre a reflexão: o que faz de um livro um livro?) levantam importantes questões sobre a não-linearidade que fundamenta o digital e as maneiras como a leitura pode ser impulsionada por livros pensados para lidar com o "user-centric", numa perspectiva que valoriza a experiência de leitura. Afinal, o que temos hoje são públicos que, quanto mais jovens, mais inseridos estarão numa nova estética da recepção, em que o foco é deslocado da leitura para o leitor e centrado na vivência do leitor junto à obra.

Parece-nos pouco eficaz, inclusive, cingirmo-nos ao argumento de que "antigamente" se lia livros impressos em seus moldes convencionais e o nível de literacia era maior. De fato, a conjugação desses dois vetores aponta-os para uma mesma direção, mas a questão implicada nos dias que correm é que, com o desenvolvimento tecnológico irrefreável, a subjetividade das novas gerações já é construída a partir de um mundo pautado pelas características do digital e em contínua permanência online, como pontua Sherry Turkle (2012). Quer dizer, a convergência nesta segunda década do século XXI exorta um mundo que, diferente do que havia no final dos anos 1990, está initerruptamente em rede em detrimento do on/off de antes.

Em última análise, o que os mecanismos de livros como os que referimos demonstram é que nenhuma obra impressa é menos complexa do que as obras computacionais. No livro impresso, por exemplo, mais do que ofertar hiperligações, é possível criar estruturas não lineares, sem qualquer eixo ou tronco pré-instituído, cuja "coluna vertebral" é estabelecida pelo leitor. Quer dizer, observando a edição impressa e a edição virtual do Composition No.1, por exemplo, num caso que nos permite claramente comparar os graus de envolvimentos do leitor nos diferentes suportes, notamos que ambas as versões possuem uma estrutura digital em que se sobressai o hipertexto, mas que o hipertexto consegue ser ainda mais eficaz na obra impressa porque o leitor tem o total controle sobre o manuseio das páginas (e essa sensação de controle é uma das características que ajudam que o défice de atenção seja menor no suporte impresso do que no ecrã), o que desfaz o mito de que só é hipertextual o que é virtual. 
Dessa forma, vemos como o contexto atual favorece a criação de novas formas de livros impressos, que ao invés de serem tratados como obsoletos ou de serem pensados em oposição ao digital/virtual, devem ser encarados num processo de retroalimentação das estruturas computacionais ${ }^{2}$. Além do mais, vê-se em obras como as exploradas neste artigo que é possível canalizar esses mecanismos dinâmicos do livro impresso no desenvolvimento da literatura infanto-juvenil. O desenvolvimento das competências de literacia pode ser estimulado a partir da valorização da pluralidade da leitura, em que a capacidade de análise é instigada pela dimensão intermédia ou pelas interfaces (de suporte e de conteúdo).

Para tanto, é importante que se estabeleça entre as convenções editoriais, à medida que as novas tecnologias de edição vão surgindo, um conjunto de protocolos de leitura que comece a valorizar o texto constelado, em que a ordem de leitura é decidida por quem lê, o que implica um leitor implícito no texto, num esforço de co-produção textual entre autor e leitor, como vimos. O texto constelado, por conseguinte, leva a uma leitura semiótica, na qual o texto não está materialmente terminado e exige uma intervenção do leitor não só hermenêutica, mas material. Isto é, o texto, cujo desenvolvimento não está pré-determinado, é na verdade um cibertexto, aqui compreendido de maneira abrangente e, portanto, não apenas para definir os textos gerados por computador, mas, como propõe Espen J. Aarseth, enquanto "the wide range (or perspective) of possible textualities seen as a typologie of machines, as various kinds of literary communication systems where the functional differences among the mechanical parts play a defining role in determining the aesthetic process" (Aarseth, 1997, p. 22).

O cibertexto demanda um esforço de leitura não naturalizado numa dimensão extranoemática, ocorrida fora do texto e de elevado grau de dimensão corporal. Não se trata só de interpretar, mas de exigir do leitor uma forma não trivial de leitura, o que permite pensar na natureza relacional dos elementos nos espaços gráficos, à espera de serem ativados pelo leitor, passando a ser intervencionados por ele. As dimensões desse cibertexto, pois, convergem para

\footnotetext{
${ }^{2}$ Um dos mais salutares exemplos das dialogias que existem entre impresso e virtual são os layouts de diagramação de vários produtos da mídia impressa, então incorporados da composição virtual, que por sua vez tem grande parte de sua construção gráfica-funcional trabalhada a partir das estruturas de organização do impresso, como podemos ver pela forma como o próprio programa Microsoft Word está concebido.
} 
que ele possua elementos de jogos, um dos principais componentes da cultura pós-moderna e que partilha várias características com a literatura digital, como uma organização plurilinear e a capacidade de permitir que o leitor, até então passivo, se torne utilizador, participante da trama e, no caso do impresso, da dimensão material do livro numa atmosfera imersiva. Afinal, os diligentes jogos, para Johan Huizinga (2004, p.10), em seu Homo Ludens, possuem "os mais nobres dons de percepção estética", o que em muito contribui para que se desenvolva nas crianças e nos jovens essa diretriz fundamental da literacia. E no caso do livro digital impresso, não se trata somente de facultar jogos metafóricos (de sentido, de linguagem, de signos múltiplos), e sim de jogos materiais a partir de estruturas topológicas de maquinaria textual.

É este o ponto fulcral, aliás, que faz com que as estruturas emuladas de Tree of Codes, Composition No.1 ou Kapow!, por exemplo, sejam diferentes das que encontramos em Julio Cortázar e o seu O Jogo da Amarelinha, publicado no início da década de 1960. Nele, o leitor decide como quer lê-lo, numa espécie de técnica inovadora para a época (embora a diagramação seja convencional), na qual o labirinto literário era uma forma de colocar em discussão os questionamentos do homem diante de seu destino - portanto, temos aqui o que podemos chamar de metáfora formal. Ou em obras de Italo Calvino, como Se um Viajante numa Noite de Inverno, já do fim dos anos 1970, em que o todo o livro é uma mesma cena narrada diversas vezes de distintas maneiras. Ou mesmo em trabaIhos do grupo Ouvroir de Littérature Potentielle, mais conhecido como OuLiPo, surgido na França dos anos 1960 e do qual o próprio Italo Calvino foi um dos expoentes. Os autores dessa corrente literária, formada por escritores e matemáticos, propuseram regras para as suas produções, tais como escrever um romance inteiro utilizando uma só vogal ou apenas a linguagem oral. Notamos que na maior parte desses casos a ousadia formal não explora exaustivamente a materialidade do livro nem a interação entre forma e conteúdo.

Portanto, o que vemos de inovador nessas novas possibilidades editoriais que surgiram na última década (e certo é que nos anos 1960 e 1970 de Cortázar ou de Calvino as tecnologias de edição eram incipientes quando comparamos com as possibilidades de hoje) não é só o registro da leitura como ato exploratório mas do texto como espaço matérico também, onde o leitor constrói um caminho multicursal e decide de que ponto quer começar a ler, criando leituras paralelas, simultâneas. O leitor está em várias partes de cada página, em cada 
parte do livro na dinâmica do códice: aquilo que cada página é, aquilo que são as sequências das laudas. Essa poética de ação material, de conhecimento artístico dos materiais leva a uma instigante natureza inventiva que resulta do dispositivo de inscrição e de intervenção gerado do ponto de vista da leitura, e não só da escrita. O resultado é uma memória coletiva ativa e uma integração da intervenção material e da intervenção crítica, pelo que esses mecanismos estimulam assim a criatividade e a autonomia crítica.

Os complexos problemas que engendram os défices de literacia crescentes a cada nova geração não serão definitivamente solucionados com uma revolução editorial, mas transformações na forma de produzir livros impressos para públicos infanto-juvenis são necessárias para que o mundo impresso não passe a ser cada vez mais distante dessas novas gerações. É preciso repensar as demandas que criam nas crianças e nos jovens uma cisão entre o mundo em que crescem e o mundo em que aprendem institucionalmente, e isto está estritamente ligado ao fato de ainda estarmos a atravessar uma fase de transição. Aliás, uma das explicações para a dificuldade de o livro impresso digital atingir o universo infanto-juvenil é que grande parte dos livros destinados a esse público são, em suma, produzidos (escritos, montados, ilustrados) por pessoas orientadas pela e para a leitura hermenêutica naturalizada e que, antes de atenderem às necessidades das crianças e dos jovens que crescem num mundo high tech, atendem às orientações dos pais (muitas vezes responsáveis por comprar os livros para os filhos e, portanto, consumidores primários), que também vêm de um paradigma pré-digital.

O fato é que a composição material dos livros que aqui exploramos não compete nem diminui a qualidade dos textos literários, dos quais muitos, como vimos, possuem mais de meio século de existência e já se encontram num processo de consolidação. Os novos formatos ajudam a ser um elo de aproximação entre o leitor e o texto, ajudam a despertar a atenção para a obra e para o contributo de que é capaz o próprio leitor com a sua perspicácia analítica e a sua capacidade criativa. No Tree of Codes, por exemplo, articular as palavras em recortes de diferentes laudas cria passagens que engendram uma memória afetiva com o livro, fazendo com que dificilmente seja uma obra ligeira.

É preciso, portanto, pensar nos mecanismos dinâmicos do livro impresso como um caminho a se investir diante da constatação de céleres mudanças na mentalidade e no comportamento de crianças e jovens, cujo acesso a ferramen- 
tas consideradas do mundo adulto, antes rigorosamente confinadas nele, dá-se bem mais cedo. Os livros impressos digitais podem facultar planos pedagógicos que atuem mais eficazmente junto aos jovens, podem viabilizar projetos que não ofertem fórmulas prontas de paradigmas que já não correspondem às realidades em que esses jovens vivem nem respondem aos seus anseios. É preciso, enfim, reaver os sentidos da materialidade do texto.

\section{Referências Bibliográficas}

AARSETH, Espen J. Ergodic Literature. In AARSETH, Espen J. Cybertext: Perspectives on Ergodic Literature. Baltimore: The Johns Hopkins University Press, 1997, 01-23 pp. ASSIS, Leonardo; PEREIRA, Wagner. No ano 2050, haverá livros, revistas e jornais impressos em papel?. Apresentação OThink. São Paulo, OThink, 2011. Disponível em: <http://knowledge.othink.com/index.php/brasil-2050/104-no-ano-2050-havera-livros-revistas-e-jornais-impressos-em-papel>. Acesso em 11 de abr. 2014.

AZZAM, Amy M. Reading at Risk. Educational Leadership. Alexandria, USA, v. 63, n. 2, out. 2005, 88-89 pp. Disponível em: <http://www.ascd.org/publications/educational-leadership/oct05/vol63/num02/Reading-at-Risk.aspx>. Acesso em 20 de jun. 2014.

Da redação. Pesquisa revela que $38 \%$ dos alunos do Ensino Superior não sabem interpretar textos. O Dia Online, Rio de Janeiro, 21 de set. 2012. Disponível em: < http:// odia.ig.com.br/portal/rio/pesquisa-revela-que-38-dos-alunos-do-ensino-superior-n\%C3\%A3o-sabem-interpretar-textos-1.465629>. Acesso em 20 de jun. 2014.

COLE, Dorian Scott. "What is Visual Writing?". The Visual Writer, 1997. Disponível em: <http://www.visualwriter.com/ScriptDr/Advanced/WhatlsVis.htm>. Acesso em 22 de jun. 2014.

ELIASSON, Olafur. Tree of Codes by Jonathan Safran Foer. Visual Editions, Londres, 2010. Disponível em <http://www.visual-editions.com/our-books/tree-of-codes>. Acesso em 20 de jun. 2014.

ESKELINEN, Markku. The Textual Whole. In ESKELINEN, Markku. Cybertext Poetics. Londres: Continuum, 2012, 67-85 pp.

FOER, Jonathan Safran. Tree of Codes. Londres: Visual Editions, 2011.

HAYLES, N. Katherine. Como Lemos Nós: Close, Hiper, Máquina. Trad. Manuel Portela. Revista de Estudos Literários, v. 2, 2012, pp. 57-96.

KIRSCHENBAUM, Matthew. The Grammatology of the Hard Drive. In KIRSCHENBAUM, Matthew. Mechanisms: New Media and the Forensic Imagination. Cambrigde, MA: MIT Press, 2008, 86-96 pp.

PORTELA, Manuel. Materialidades da Literatura. In CARDOSO, Catarina Figueredo; BA- 
RAONA, Isabel. Portuguese Small Press Yearbook. Lisboa: Várzea da Rainha Impressores, 2013, 15-22 pp.

PORTELA, Manuel. Introdução: Literatura no Século XXI. Revista de Estudos Literários, v. 2, 2012, 5-22 pp.

SAPORTA, Marc. Composition No.1. Londres: Visual Editions, 2011.

SCHREIBMAN, Susan. Digital Scholarly Editing. Literary Studies in the Digital Age: An Evolving Anthology. Nova lorque, MLA, v. 10, n.1632/lsda, 2013. Disponível em: <http://dlsanthology.commons.mla.org/digital-scholarly-editing/>. Acesso em 14 de jun. 2014.

STERNE, Laurence. The Life and Opinions of Tristram Shandy, Gentleman. Londres: Visual Editions, 2010.

THIRLWELL, Adam. Kapow!. Londres: Visual Editions, 2012.

TURKLE, Sherry. Alone Together. Nova lorque: Basic Books, 2012. 